"Critical assessment of Public Transportation System (PTS) and its implication on environmental economics through service delivery"

\begin{tabular}{|c|c|c|}
\hline AUTHORS & \multicolumn{2}{|l|}{$\begin{array}{l}\text { Kassian Amesho } \\
\text { Emmanuel Innocents Edoun }\end{array}$} \\
\hline ARTICLE INFO & \multicolumn{2}{|c|}{$\begin{array}{l}\text { Kassian Amesho and Emmanuel Innocents Edoun (2016). Critical assessment of } \\
\text { Public Transportation System (PTS) and its implication on environmental } \\
\text { economics through service delivery. Environmental Economics, 7(4), 34-47. } \\
\text { doi:10.21511/ee.07(4).2016.04 }\end{array}$} \\
\hline DOI & \multicolumn{2}{|c|}{ http://dx.doi.org/10.21511/ee.07(4).2016.04 } \\
\hline RELEASED ON & \multicolumn{2}{|l|}{ Friday, 09 December 2016} \\
\hline JOURNAL & \multicolumn{2}{|l|}{ "Environmental Economics" } \\
\hline FOUNDER & \multicolumn{2}{|c|}{ LLC "Consulting Publishing Company "Business Perspectives" } \\
\hline & & $\begin{array}{l}=-5 \\
= \pm=\end{array}$ \\
\hline NUMBER OF REFERENCES & NUMBER OF FIGURES & NUMBER OF TABLES \\
\hline 0 & 0 & 0 \\
\hline
\end{tabular}

(C) The author(s) 2021. This publication is an open access article. 
Kassian Amesho (Taiwan), Emmanuel Innocents Edoun (South Africa)

\title{
Critical assessment of Public Transportation System (PTS) and its implication on environmental economics through service delivery
}

\begin{abstract}
The ever-increasing traffic congestion echelons and the subsequent undesirable air quality in several metropolitan areas have raised the need for a successful public transportation system to ease the dependence on the private automobiles. Also the environmental economics is becoming more and more appealing taking into consideration different activities that have economic impact. One of such activities is public transportation. In the current scenario of globalization, public transportation services and systems need to perform introspective contemplation towards the quality of services offered (Michel, 2011). The research adopted a quantitative method of inquiry, therefore, a Survey Research Strategy was considered in order to provide a quantitative or numeric description of trends, attitudes, or opinions of a population by studying a sample of that population. It includes cross-sectional and longitudinal studies using questionnaires or structured interviews for data collection, with the intent of generalizing from a sample to a population (Babbie, 2010). In this context, this research study anticipated to critically evaluate the customers' perception of the public transportation system and its impacts on service delivery: a case study of Busan Metropolitan City, Korea Republic. This paper is divided into five major sections.
\end{abstract}

Keywords: environmental economics, public transportation system, customer perceptions, managerial perspective, customers.

JEL Classification: Q50, Q56, R11, P43.

\section{Introduction}

Miller (2013) has highlighted that public transportation is an efficient and environmentally friendly alternative to automobiles. It is also important to the social fabric of a city, as it provides access to shelter, food, employment, schooling, medical care, and entertainment to people who, because of age, income, or disability, do not have regular access to private motor vehicles (Jones, 1985; Small and Gomez-Ibanez, 1999; Iseki and Taylor, 2008). In a country like United States of America (USA), the important role of transit systems to society has led to their heavy subsidization. However, according to the American Public Transportation Association (2005), in 2002 alone, transit providers nationally received about $\$ 12.8$ billion in capital funds from various sources, with $41 \%$ from the federal government, $12 \%$ from state sources, $20 \%$ from local sources, and the remainder from taxes levied by transit agencies and other directly generated sources.

Vijay (2013) has strongly acknowledged that service quality is generally predicted as the sum of customer perceptions of the service experience. While Parasuraman, Zeithaml and Malhotra (2005) believed that the difference between service quality and satisfaction is perceived, service quality is a

(c) Kassian Amesho, Emmanuel Innocents Edoun, 2016.

Kassian Amesho, Institute of Environmental Engineering, National Sun Yat-sen Universisty, Taiwan.

Emmanuel Innocents Edoun, Dr., Senior Lecturer, Tshwane University of Technology, Business School, South Africa. global judgment, or attitude, relating to the superiority of the service, whereas satisfaction is related to the specific transaction (Parasuraman et al., 2005). Customers form service expectations from many sources, such as past experiences, word of mouth, and advertising. Sahu (2006) argued that customers, on numerous occasions, compare the perceived services with the expected service. If the perceived service falls below the expected service, customers are dissatisfied and if the perceived service quality is above the expected level, it creates satisfied customers. Gronroos and Ojasalo (2004) believed that marketers need to understand that customers are more than mere consumers of service quality output; they are co-producers of the quality process. According to Ancarani and Capaldo (2001), service quality has become a significant differentiator and the most influential modest weapon which many service organizations possess.

\section{Literature review}

Literature review for this study is primarily focused on the theory that public transportation system and its impact on service delivery is driven by customers' perception and satisfaction. The research process began with a review of applicable literature to assist in forming a foundation of background knowledge and topics of discussion for the research process. Purposive sampling will be used to identify participants for this research study. This study will draw on the diverse approaches to studies pertaining to the evaluation of the customers' perception of the public transportation system and its impacts on service delivery. 
Service quality is generally visualized as the sum of customer perceptions of the service experience (Johns, 1992). Parasuraman, Valarie, Zeithaml and Berry (1988) suggested that the difference between service quality and satisfaction is perceived, service quality is a global judgment, or attitude, relating to the superiority of the service, while satisfaction is associated to the specific transaction. Public transportation is defined as transportation by a conveyance that provides continuing general or special transportation to the public; excluding school buses, charter and sightseeing service. Public transportation includes various modes such as buses, subways, rail, trolleys and ferry boats (Berita Jakarta, 2009). Public sector organizations including transportation services are created by governments with an intention not to compete in the open market, rather their objective which is to fulfill the needs of common public. As public transport organizations grow older and mature, the quality of service dwindles down with the public, particularly the customers/commuters being left with no option, but to accept what is offered (Andreassen, 1994). In order to help this situation, the concept of quality needs to be introduced into public transportation for meeting the quality expectations of the public (Ancarani \& Capaldo, 2001).

Over the last few years, the service companies or organizations have progressively focused on the service quality and the customers' satisfaction. This approach is very beneficial for both service providers and customers, especially for transit organizations and passengers. But the reality is that an improvement of the supplied service quality can attract further users. Moreover, in the service industries, the evaluation of the service quality is challenging primarily because of the insubstantial nature of the services (Ida, 2012). A study by Vijay (2013) revealed that providing service transportation which is adequate and appropriate is always the challenge that encountered in almost all cities all over the world. And large cities will always have a new problem emerging, which arises due to transportation system. Anderson, Condry, Findlay, Brage-ardao and $\mathrm{Li}$ (2013) argued that service quality and convenience is of increasing importance to all businesses, including public transport organizations. Thus, it influences customer satisfaction, passenger demand, investment decisions and revenue. Klaus (1985) argued that service quality is a phenomenon experienced by individuals and is manifested in individual behavior. It is also a dynamic, complex configuration of physical, situation, and behavioral variables. Klaus (1985, p. 24) defined quality as "the shared experience of gain by participants and stable pattern of behavior associated with a given type of service encounter". Primarily, review of the literature showed lack of consensus with respect to the evaluation of customers' perception of the public transportation system and its impacts on services delivery. However, past studies have examined customers' perception of the public transportation system and its impacts on service delivery from a diverse perspective. According to the outcome-oriented evaluations, the customers' perception of the public transportation and its impacts on service delivery can be appreciated as a summation of satisfactions with various attributes (Ercsey and Józsa, 2009).

Satisfaction can be defined as an experience of fulfillment of an expected outcome. Satisfaction or dissatisfaction with a program or facilities is influenced by prior expectations regarding the level of quality (Sigala, 2004). Satisfaction depends on numerous factors and there is no dearth of literature on this subject. To generate the factors leading customer satisfaction, we look at some research studies done in this field. Studies conclude that customers want the best service quality and respond as well to what they want (Zheng and Jiaqing, 2007). Based on the literature, it is evident that the evaluation of customers' perspective of the public transportation and its impacts on service delivery depends not only on the service attributes fulfilment, but also on the prospects. The expectation in this regard is knowledge collected about service quality (Ercsey and Józsa, 2009) and this expectation can affect positive customers' satisfaction (Anderson, Fornell and Lehmann, 1994). Mittal, Kumar and Tsiros (1999) pointed to dynamics of satisfaction, so the importance of factors that determine the total consumer satisfaction changes from time to time.

The background for evaluating the customers' perception of public transportation system and its impacts on service delivery in public transportation envisages the broad dimensions tangibility, reliability, responsiveness, assurance and empathy given by Parasuraman et al.'s (1988) model for evaluating service quality. Population specific characteristics and public transportation specific determinants influence the generic dimensions. Evaluation of customers' perception of the public transportation system and its impacts on service delivery consists of internal and external factors, which affect the customers or commuter's perception towards the public transportation system (Alshalalfah and Shalaby, 2005). Internal factors such as strategic issues (Eboli and Mazzulla, 2011), top management commitment, service quality standards, monitoring systems (Anderson, Allport and Findlay, 2012), customer complaints handling 
system (Kotler and Kavin, 2008) and external factors such as alternative services (e.g., private services, auto-rickshaws, own vehicles) (Evans and Shaw, 2001; Michel, 1999), frequency of traveling and timings (Flem and Schiermeyer, 1997; Galetzka, Gelders, Verckens and Seydel, 2008), convenience and comfort, climate, ego, social status, professions (Sanchez, 1999).

Several researchers have argued that customer feedback and complaints are key drivers for improving different aspect of business and may help the provider to develop a sustainable company. Therefore, an effective complaint management process can be an important quality improvement instrument. This argument has been complemented by various studies which highlighted that customers feedback and complaints should be welcomed and reinvigorated by the service provider, because they generate valuable information (Graham, Crotte and Anderson, 2009; Melo et al., 2011; Barron, Melo, Cohen and Anderson, 2013). In case of the transport activities, satisfaction/dissatisfaction is a rational, emotive response based on the subjective evaluation process (Karlaftis et al., 2001). Focus of satisfaction: attributes of public transport, physical facilities, and personnel. Researchers about consumer satisfaction agree that satisfaction is an essential component for economic success (Stauss and Neuhaus, 1997; Muffatto and Panizzolo, 1995). The consumer will be satisfied if the service gives value for him/her (Dumond, 2000).

This value is one of the most important connections between the cognitive components of perceived quality, the experienced performance, and future behavior directed towards the company (Patterson and Spreng, 1997). From the literature, it is evident that the satisfaction depends not only on the service attributes fulfilment, but also on the expectations. The expectation is knowledge collected about service quality (Ercsey and Józsa, 2009) and this expectation can positively affect consumer satisfaction (Anderson, Fornell and Lehmann, 1994). Mittal, Kumar and Tsiros (1999) pointed to dynamics of satisfaction, so the importance of factors that determine the total consumer satisfaction changes from time to time. According to Krizek and El-Geneidy (2007), the analyzes about satisfaction examination concentrate output and are not in connection with inside processes of company, so the researchers have to make the process-oriented satisfaction examination.

Customers' complaints may be useful in many ways such as providing marketing intelligence data, identifying common service problems, learning about organization, improving service design and delivery, measuring and enhancing the perception of service quality, and helping strategic planning (Lai and Chen, 2011). This means that a customer who does not complain to the service provider when having an unfavorable service experience is of particular concern to any service company. That being the case, it is generally accepted that obtaining feedback from customers' service experiences is important and if the provider fails to obtain such valuable feedback, the opportunity to remedy the problem and retain the customer is lost. As a result, the company's reputation can also suffer damage from negative wordofmouth among dissatisfied customers. This is often asserted that lack of feedback from dissatisfied customers represents a loss of potential and current customers. Therefore, it is important to understand the customer's service evaluation through increased knowledge about the behavioral process and in the case of unfavorable service experience, the complaint behavior (Lai and Chen, 2011).

\section{Research methodology}

A self-administered questionnaire and interview administered questionnaires approach have been employed for this research study. The selfadministered questionnaire and interview administered questionnaires allows the researcher to utilize information gained from questionnaires in forming a supposition, as opposed to the conventional method of, first, forming a hypothesis, then, seeking to prove it through questionnaires (Roberts, 2003). The primary purpose of the questionnaires is to understand and critically evaluate the customers' perception of the public transportation system and its impacts on service delivery in Busan Metropolitan City, the Republic of Korea. Questionnaires were distributed with the permission of the participants to allow the researcher to focus on the distribution and collection to ensure more questionnaires have been completed.

2.1. Research strategies. According to O'Leary (2004), every research project encompasses a range of activities in the research process; namely, from study design to data management, to data exploration to statistical modelling and, finally, to the reporting of results. Of these five stages, each requires important research method inputs all of which need to be considered at the outset when putting together a research strategy. Thus, research strateg yis the activity that needs to be undertaken to ensure that there are adequate resources available to complete the study in the time available, to make sure that the approach to the design of the study is the appropriate one to achieve the study's objectives, that suitable softwares are available to 
manage and analyze the data, that sensible sets of data are collected to ensure that analysis will allow the required information to be extracted, and so on (Ford, 2000).

2.2. Surveys. This research study has employed the Survey Research Strategy in order to provide a quantitative or numeric description of trends, attitudes, or opinions of a population by studying a sample of that population. It includes cross-sectional and longitudinal studies using questionnaires or structured interviews for data collection, with the intent of generalizing from a sample to a population (Babbie, 2010).

2.3. Research study design. A cross-sectional survey study was used as a research design to complete this research study. This research study intended to critically evaluate the customers' perception of the public transportation system and its impacts on service delivery in Busan Metropolitan City, the Republic of Korea. This study aimed at an in-depth understanding of customer perceptions and responses to address travel-experience creation in the context of mobile technologies and, as such, a qualitative approach was adopted. Interviews and focus group discussion were adopted as the appropriate methods to identify value perceptions that customers were able to verbalize. The customer interviews were done mainly at the metro stations in Chengdu, China, and at the campus of Southwest Jiaotong University. The respondents were selected within such areas with a preference for young and highly-educated people, because such groups of people tend to favor self-service technologies using mobile devices (Meuter et al., 2000).

2.4. Target population. John (2007) defined sample as a portion or subset of a larger group called a population. While generalizability refers to the extent to which we can apply the findings of our research to the target population we are interested in. As for this research study, the population target is Busan Metropolitan City. According to Busan Transportation Corporation (2016), the Busan Metropolitan City has a population of approximately 3.6 million.

2.5. Size of the sample and sampling procedures. Pasek (2012) has contended that there are principally two methods or sampling, namely, probability and non-probability. Purposive random sampling looks at a random sample. This type of random sampling uses small sample sizes, thus, the goal is credibility, not representativeness or the ability to generalize. This reduces judgment within a purposive category, because the cases are picked randomly and without regard to the program outcome. Determining sample size is a very important issue, because samples that are too large may waste time, resources and money, while samples that are too small may lead to inaccurate results. In many cases, researchers can easily determine the minimum sample size needed to estimate a process parameter, such as the population means (John, 2007).

2.6. Size of the sample. This study collected about 187 samples through research questionnaires on a convenient basis from four (4) major commercial centers and transportation hubs in Busan Metropolitan City, namely: Seomyeon, Nampoo Dock, Sasang and Gimahea, with a sample population of approximately 50 from each of the four major commercial centers and transportation hubs.

2.7. Sampling procedures. This study adopted stratified random sampling techniques in order to carry out this survey. The samples were taken from four (4) major commercial centers and transportation hubs in Busan Metropolitan City, namely: Seomyeon, Nampoo Dock, Sasang and Gimahea, with a sample population of approximately 50 from each of the four major commercial centers and transportation hubs. The study sample target initially was 200 commuters. But duly completed and returned questionnaires were 187, giving a response rate of $93.5 \%$ (187) of the respondents who participated in this study. This response rate was considered good for this type of study. The participants were solicited through their respective major commercial centers and transportation hubs in Busan Metropolitan City. Data were collected through self-administered questionnaires. Questionnaires have been filled by participants and for accuracy; all participants were informed that their responses would remain confidential.

2.8. The research instrument. Data collection or research instruments are usually chosen on the basis of their suitability to answer the research problem. Therefore, no single instrument of data collection can inherently be regarded as better than other techniques. The success of data collection lies in the extent to which it can be relied upon and the validity of the results it provides. This study has employed quantitative research method. The research instruments that have been used were research questionnaires or surveys (self-administered questionnaires). The research study relied on a quantitative research design by making use of primary sources of information. The researcher has used these research instruments to collect complete data that will be useful to critically evaluate the customers' perception of the public transportation system and its impacts on service delivery in Busan Metropolitan City, the Republic of Korea. Research questionnaires or surveys are very flexible and can be used to collect different types of data from small or 
large numbers of people. Research questionnaires or surveys were used due to the fact that they often gather quantitative data, but can also gather qualitative information through open-ended questions. Hence the appropriateness to the study.

2.9. Questionnaire construction. The research questionnaire for this study was constructed with 14 questions. The questions were categorized into two. Seven (7) questions seek demographic information such as age group, gender, marital status, educational level, and employment status among others. Another seven (7) questions were constructed with regards to customers' perception of the public transportation system and its impacts on service delivery in Busan Metropolitan City, the Republic of Korea on all six (6) factors, namely: tangible, reliability, responsiveness, assurance, compassion, and culture. The perception questions were constructed on the basis of a psychometric response scale, which is primarily used in questionnaires to obtain participant's preferences or degree of agreement with a statement or set of statements. These seven (7) questions on perception were constructed on a Likert scale which is a non-comparative scaling technique and are unidimensional (only measure a single trait) in nature (Page-Bucci, 2007).

2.10. Data analysis. The data for this research study will be collected through answering questionnaires. The data will be compiled and analyzed in a computer.
The research instrument questionnaires will be sorted and coded first before entered into the computer for analysis. Data management will be done with the use of computer software package such as Statistical Package for Social Science (SPSS) version 19.0, as well as descriptive statistics and crosstabs methods such as tables, charts, graphs, frequency distribution tables as appropriate statistical methods to analyze these data, and results obtained will be published. The results will be presented using descriptive statistics components and, among others, tables, charts, graphs, frequency distribution tables, etc. On the reliability, this research study will appropriate statistical tests such as t-test, to provide a mechanism for making quantitative decisions about a process or processes. The intent is to determine whether there is enough evidence to reject a conjecture or hypothesis about the process.

\section{Results discussions and findings}

3.1. Introduction. The purposes of this study is to critically evaluate the customers' perception of the public transportation system and its impact on service delivery: a case study of Busan Metropolitan City, the Republic of Korea. The response rate for this research study was $93.5 \%(\mathrm{n}=187)$.

3.2. Socio-demographic information. Frequency distributions were obtained to check for data entry errors and to obtain descriptive statistics for age group of research respondents, as indicated in Figure 1.

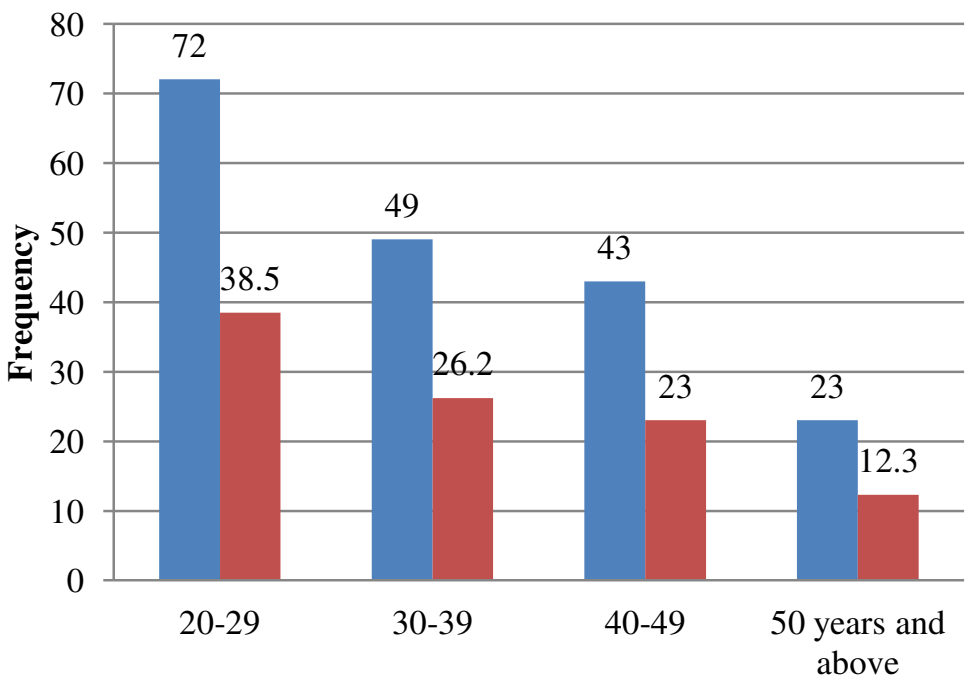

Age group of respondents

Fig. 1. Frequency and percentage on age group of research respondents

The results show that majority of the research participants or respondents in this study are mostly the youth population within the range of 20-39 years old. This accounts for about $38.5 \% \quad$ (72) and $26.2 \%$ (49) of the research respondents, respectively, whilst $23 \%$ (43) of the research respondents falls under the age range of 40-49 years old. Only $12.3 \%$ (23) of the research respondents are above were 50 years old and above. 
Table 1. Educational background or qualification of research respondents

\begin{tabular}{|l|c|c|}
\hline \multicolumn{1}{|c|}{ Qualification } & Number of respondents & Percent (\%) \\
\hline Graduate & 88 & 47.1 \\
\hline Postgraduate & 41 & 21.9 \\
\hline Others & 58 & 31.0 \\
\hline Total & 187 & 100 \\
\hline
\end{tabular}

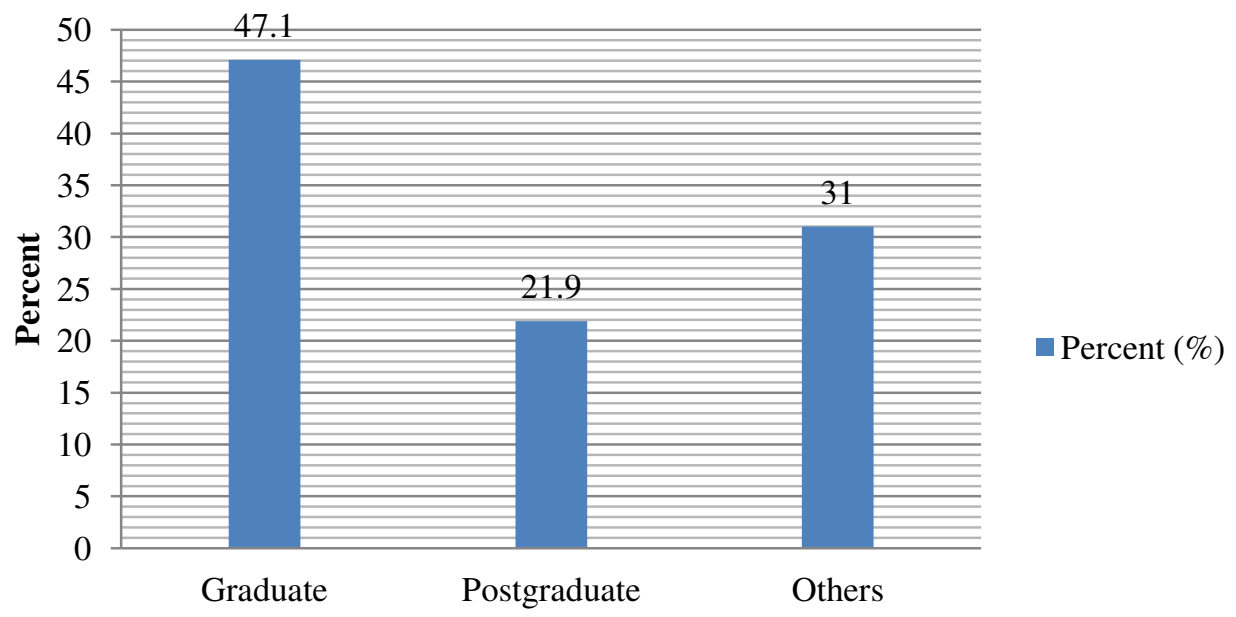

\section{Educational background or qualification}

Fig. 2. Educational background or qualification percentage of research respondents

By analyzing the data gathered from questions in the postgraduate education. But $31 \%$ (58) of the questionnaires, the results have revealed $47.1 \%$ (88) research respondents indicated that their educational of the research respondents falls under graduate background is "Others", that is, neither graduates education, while $21.9 \% \quad(41)$ falls under nor postgraduates.

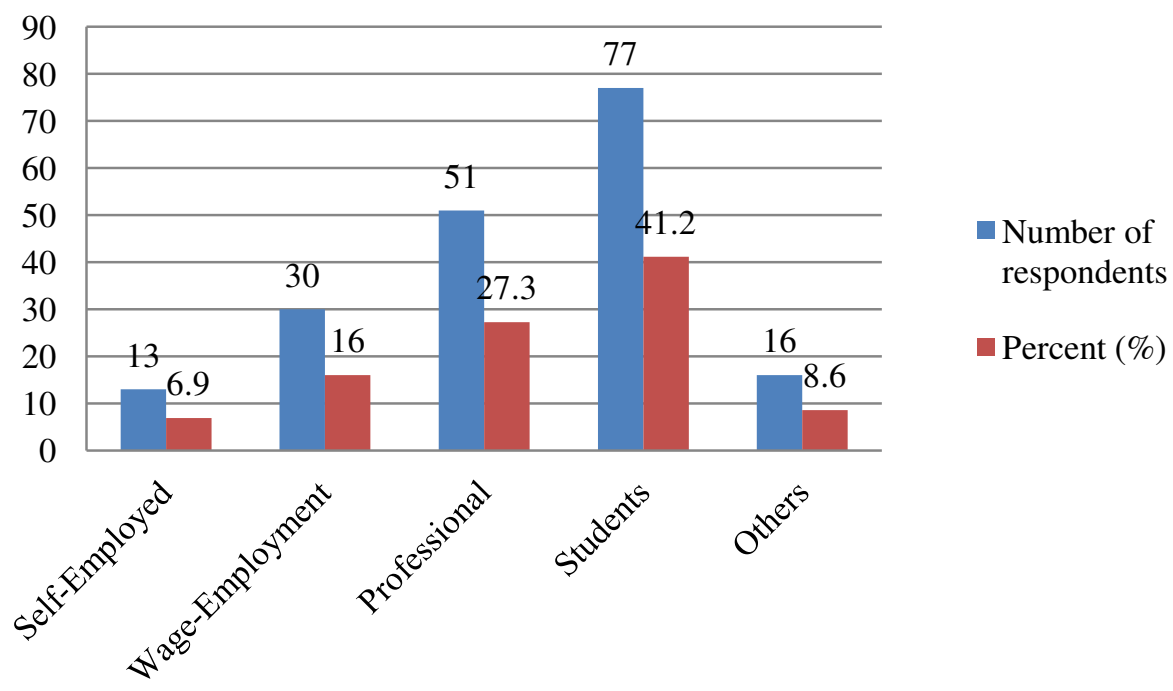

Fig. 3. Employment status percentage of research respondents 


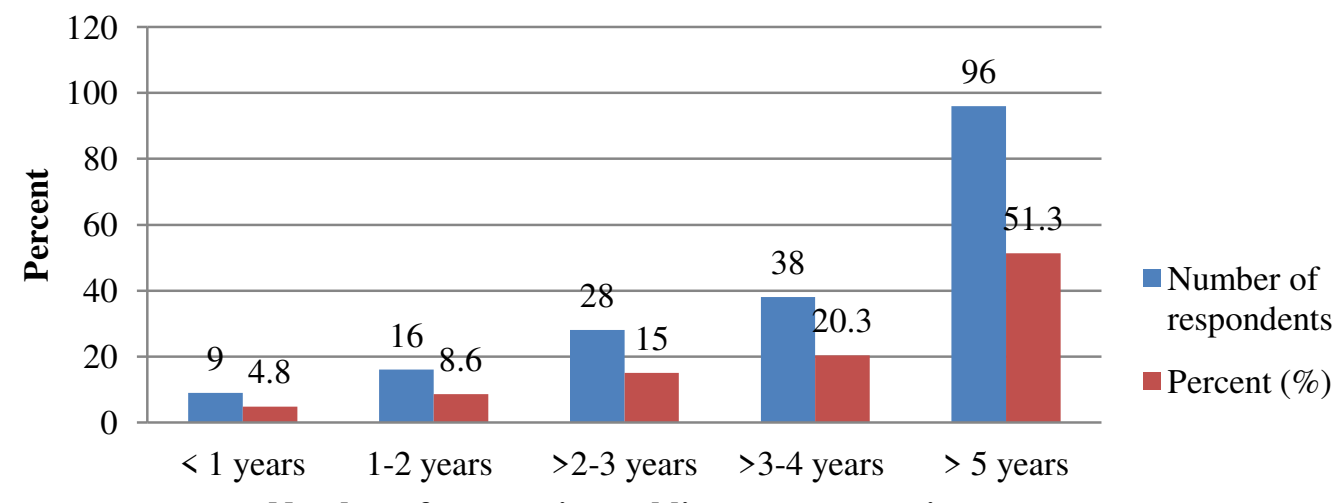

Number of years using public transport services

Fig. 4. Public transport service experience percentage of research respondents

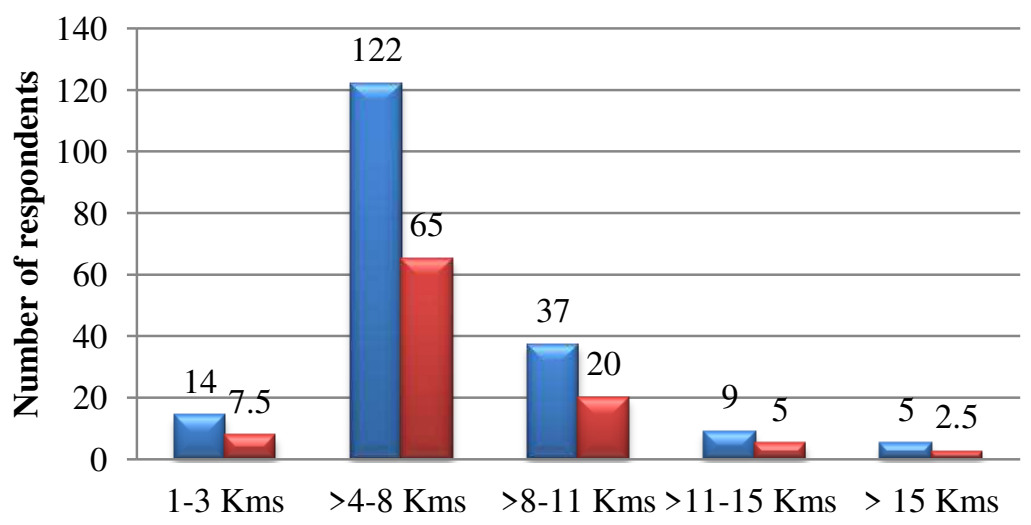

Number of respondents

$\square$ Percent $(\%)$

Fig. 5. Distance traveled everyday when using PTS percentage of research respondents

\subsection{Preliminary question.}

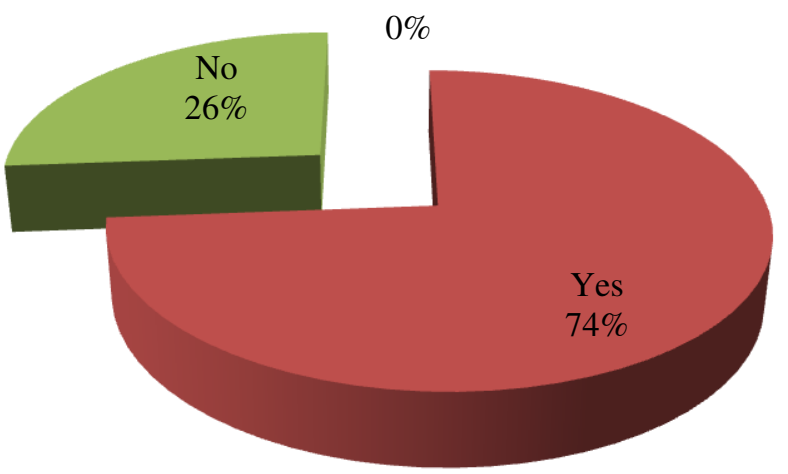

Fig. 6. Regular commuters using public transportation system (PTS) percentage of research respondents 


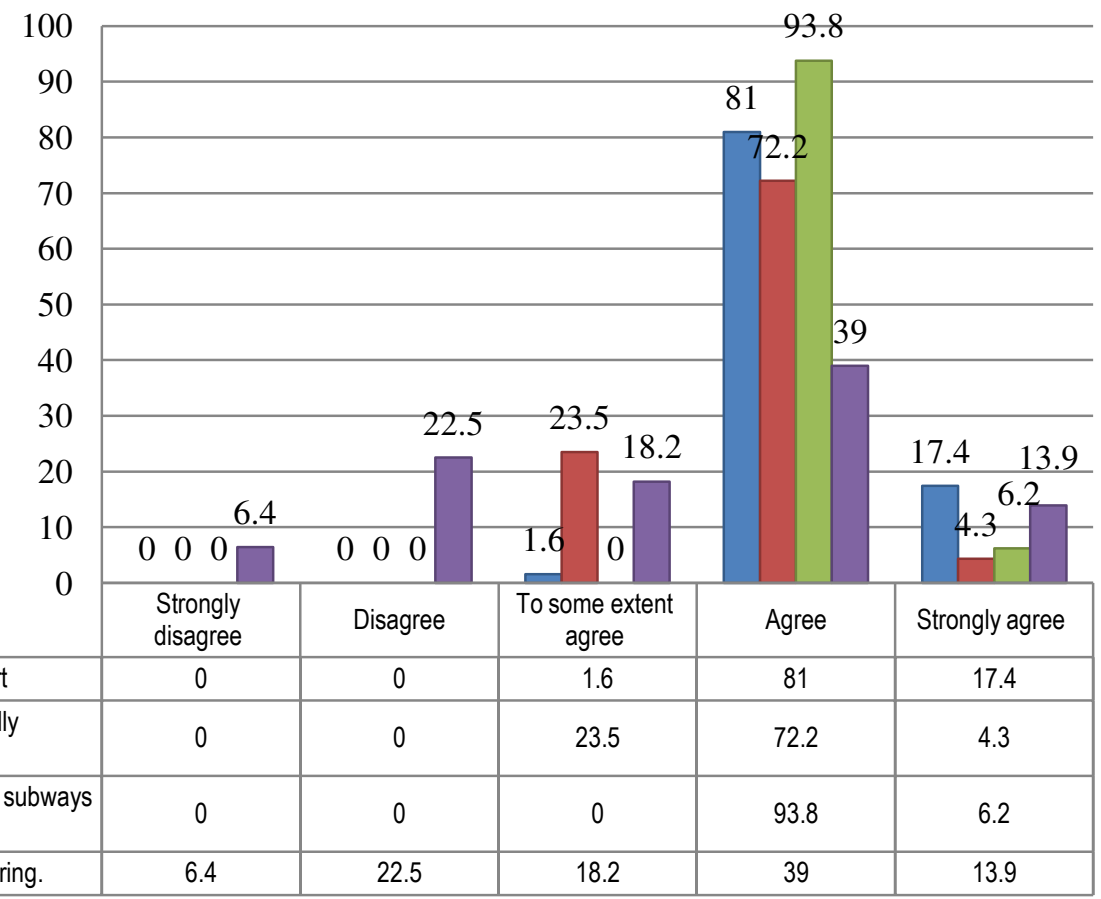

Fig. 7. Level of perception on tangible about PTS percentage of research respondents

On the preliminary question about whether the research participants are commuters who regularly use public transportation system, 73.8\% (138) of the research respondents have indicated that they regularly use PTS by answering YES. But nonetheless, $26.2 \%$ (49) of the research participants have revealed that they are NOT regularly using PTS. The level of perception of customers about the public transportation system
(PTS) in Busan Metropolitan City and its impact on service delivery was measured, evaluated and analyzed on six (6) factors, namely: tangible, reliability, responsiveness, assurance, compassion, and culture. Measures of variables in the model using 5-point likert scales (anchored at strongly agree [5], agree [4], to some extent agree [3], disagree [2] and strongly disagree [1]) (Parasuraman et al., 2005).

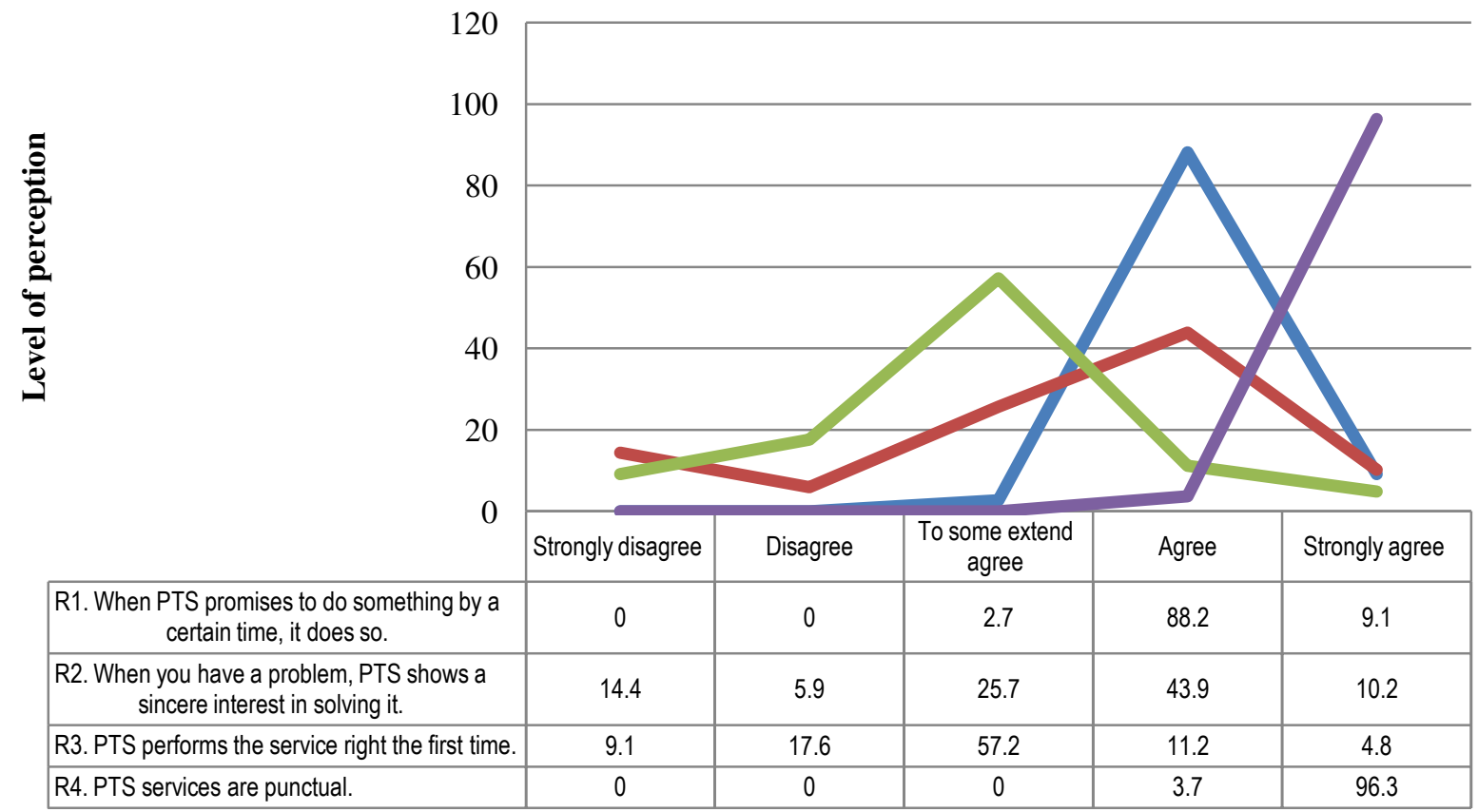

Fig. 8. Level of perception on reliability about PTS percentage of research respondents 


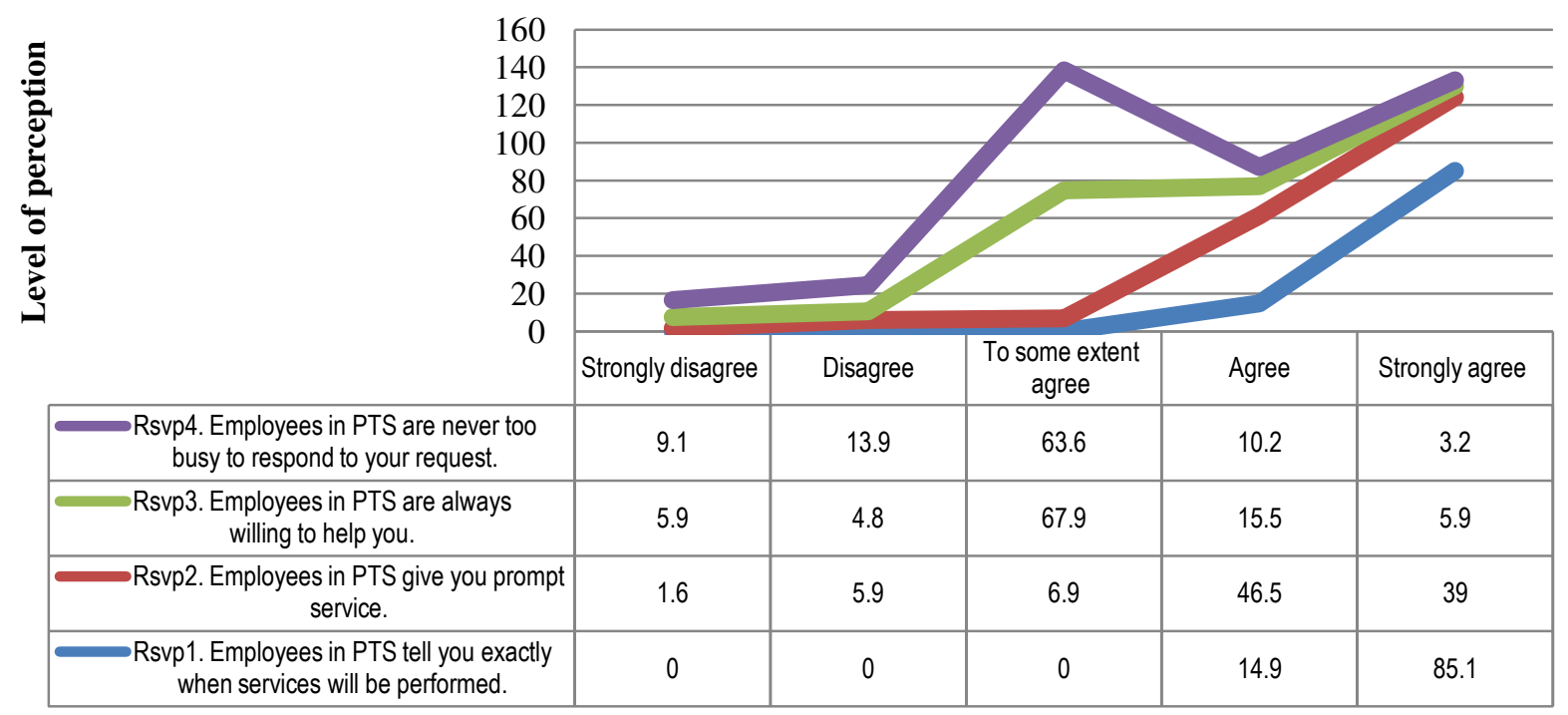

Fig. 9. Level of perception on responsiveness about PTS percentage of research respondents

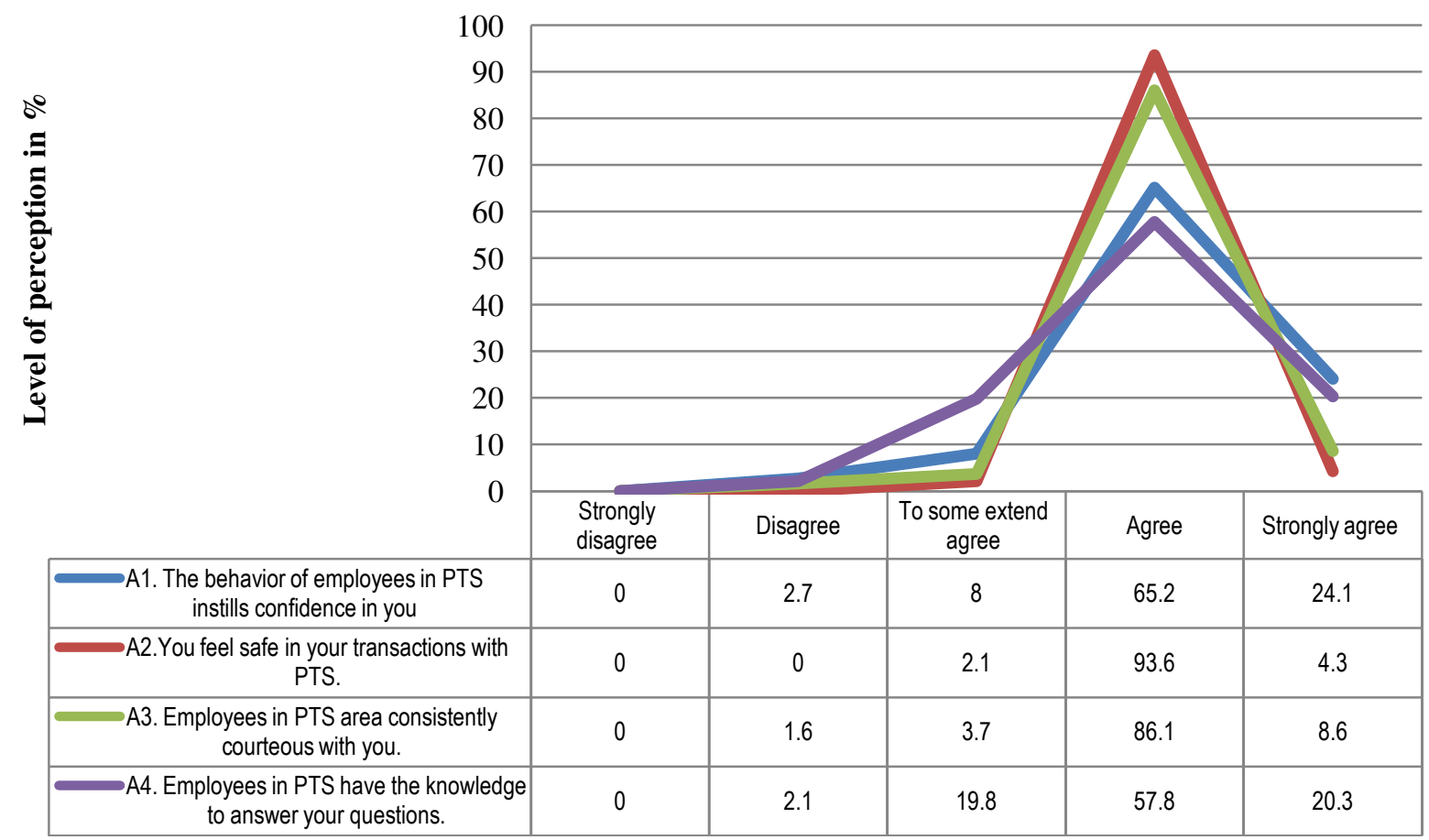

Fig. 10. Level of perception on assurance about PTS percentage of research respondents 


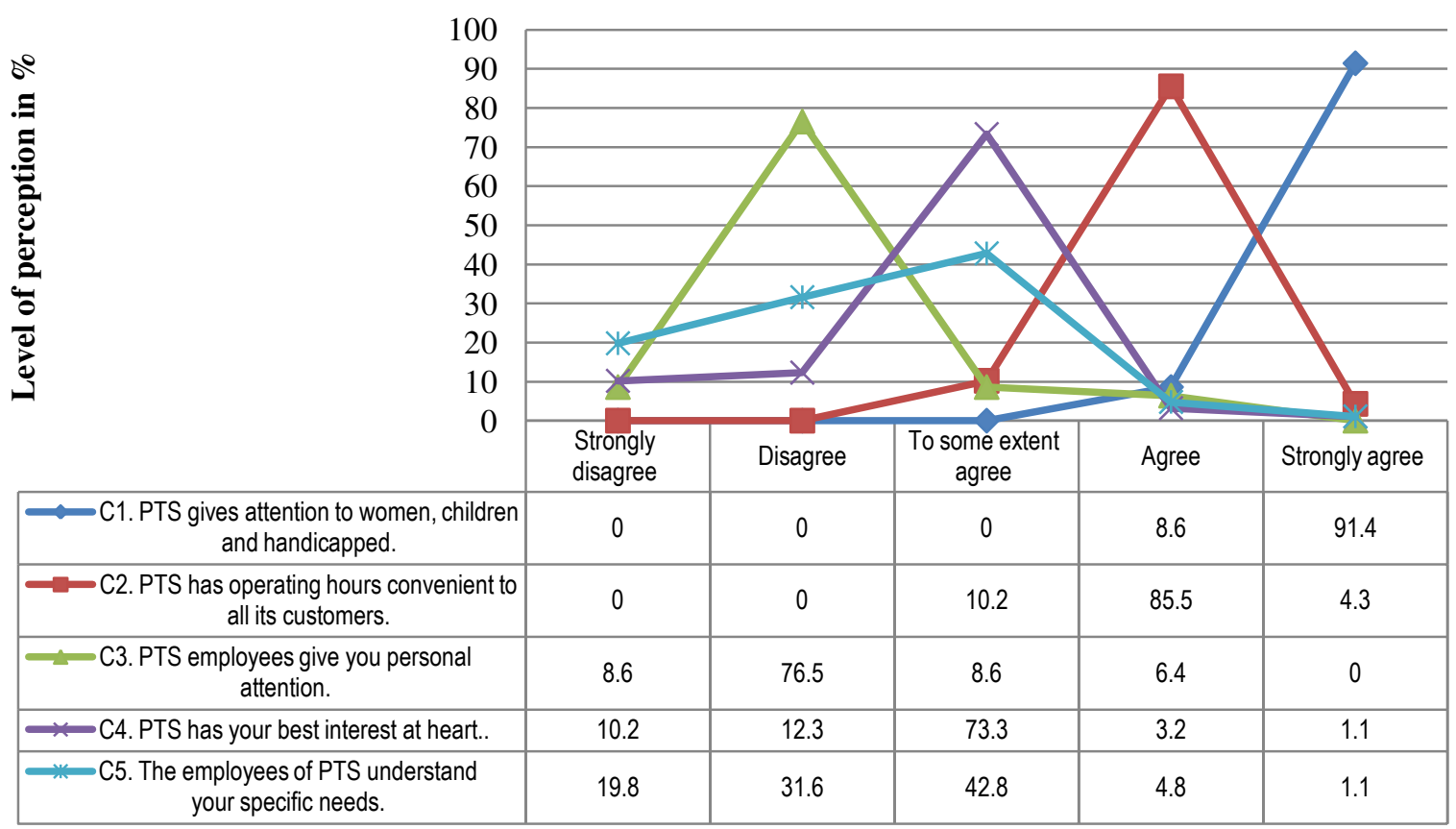

Fig. 11. Level of perception on compassion about PTS percentage of research respondents

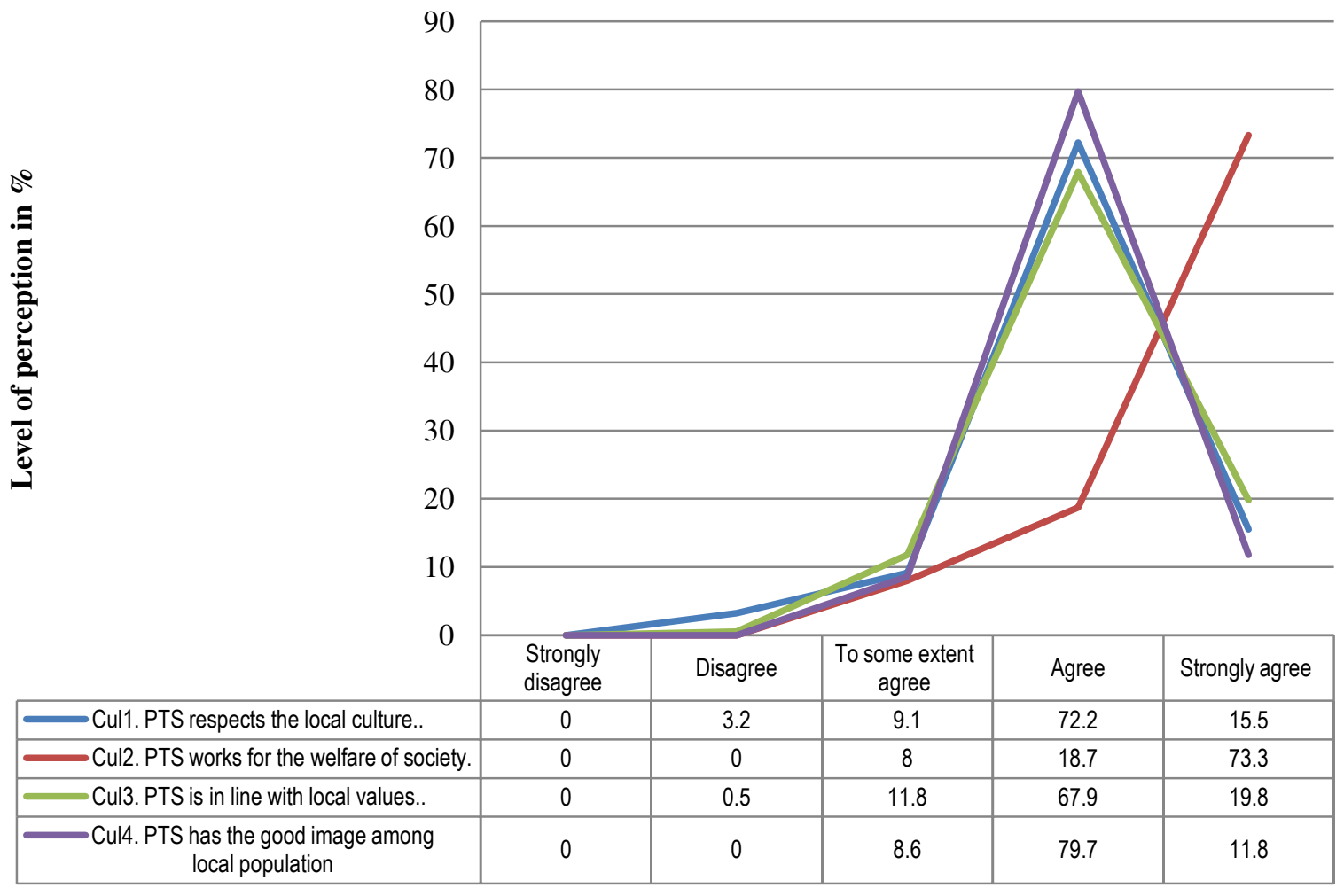

Fig. 12. Level of perception on culture about PTS percentage of research respondents

The findings upon results analysis have revealed that the research respondents, overall, have positive perceptions towards PTS in Busan Metropolitan City. The findings are also within the theoretical framework of the research theory that public transportation system (PTS) and its impact on service delivery is driven or determined by customers' perception and satisfaction. This is also confirmed by the findings which, overall, show the customers' satisfaction about PTS and its impact on service delivery in Busan Metropolitan City, as the respondents couldn't show much negative or complaints about PTS and its service delivery. This is a positive complement to the Busan Transportation Corporation, an institution which is responsible for public transportation system in the 
entire Busan Metropolitan City. These findings are encouraging and would help the Busan Transportation Corporation to re-evaluate the transportation system in place, in order to meet the fast growing population of Busan Metropolitan City. The level of perception of customers about PTS and its impact on service delivery was measured, evaluated and analyzed on six (6) factors, namely: tangible, reliability, responsiveness, assurance, compassion, and culture.

\section{Conclusion and recommendations}

Findings from the study. The study found that the youths from 20-39 years of ages are the most customers or commuters that are frequently using the public transportation system in Busan Metropolitan City. This is most probably, because this age group from 20-39 is the most productive age group in any workforce or society and, on numerous occasions, they are students, hence there ia a necessity of using public transport to go from one place to another. Moreover, the study has also revealed that customers or commuters in Busan Metropolitan City are mostly and on numerous occasions traveling a distance of 4-8 kilometers (Kms) everyday whenever suing PTS. Frequency distributions were obtained to check for data entry errors and to obtain descriptive statistics for age group of research respondents, as indicated in Figure 1. The results show that majority of the research participants or respondents in this study are mostly the youth population within the range of 20-39 years old. This accounts for about 38.5\% (72) and $26.2 \%$ (49) of the research respondents, respectively, whilst 23\% (43) of the research respondents falls under the age range of $40-49$ years old. Only $12.3 \%$ (23) of the research respondents are above were 50 years old and above. Also, by analyzing the data gathered from the questionnaires, the results have revealed $47.1 \%$ (88) of the research respondents falls under graduate education, while $21.9 \%$ (41) falls under postgraduate education. But $31 \%$ (58) of the research respondent indicated that their education background is "Others", that is, neither graduates nor postgraduates. On the preliminary question about whether the research participants are commuters who regularly use public transportation system, 73.8\% (138) of the research respondents have indicated that they regularly use PTS by answering YES. But nonetheless, 26.2\% (49) of the research participants have revealed that they are NOT regularly using PTS. The level of perception of customers about the public transportation system (PTS) in Busan Metropolitan City and its impact on service delivery was measured, evaluated and analyzed on six (6) factors, namely: tangible, reliability, responsiveness, assurance, compassion, and culture.
Measures of variables in the model using 5-point likert scales (anchored at strongly agree [5], agree [4], to some extent agree [3], disagree [2] and strongly disagree [1]) (Parasuraman et al., 2005).

Findings from the literature review. This study has some common findings with previous studies. Comparable to Eboli and Mazzulla's (2012a) research, this study reveals that customer/commuter transportation services have a structure that differentiates technical requirements into two branches. The first branch describes the tangible features of the transportation services (modern looking transport or physical facilities are visually appealing and the specifications of the buses), whereas the second one emphasizes subjective features less easily measurable (competency of employees and empathy of employees). Vanniarajan and Stephen (2008) discovered that empathy, compassion or responsiveness is one of the key determinants of service quality in transportation services, which was also found in this study and, eventually, agreed with the initial study. Cirillo et al. (2011) and Vanniarajan and Stephen (2008) also emphasized the competency of employees and the specifications of the buses in the transportation services as similar findings to this study. In another correspondence with the previous studies, Nathanail's (2008) study took into consideration the itinerary accuracy needed for the technical requirement of error free service, as we also found in this study under reliability factor. Although this study resulted in similar findings given in previous studies, there are also some differences. For example, reliability and culture are among the most important dimensions in service quality.

Acquiring new customers and retaining existing customers has long been important consideration in gaining competitive advantage. Zeithaml et al. (1996) suggested that increasing customer retention is a major key in generating profits, while Eboli and Mazzulla (2012) stated that it is important to provide high quality customized services to retain customers and attract new users. When service quality considered an important factor for creating differentiation in a service industry, the importance of determining the level of service quality provided to customers is emphasized. Increasing service quality is difficult for service firms, compared to those producing goods, because services are intangible, heterogeneous, perishable, and inseparable (Hoffman and Bateson, 2006). Estimating service quality provides service firms with information that allows them to create knowledge that their marketing operations can use appropriately. 
Recommendations. The main purpose of these recommendations is to improve urban livability and/or sustainable transportation but, when carefully designed and implemented, they can also help to

improve public transport operations. Furthermore, including these types of recommendations in comprehensive programs to improve public transportation system priority helps to increase community support for public transport and create more dynamic urban environments, thus, further increasing demand for good public transport service (Nash, 2006). Public transportation system (PTS) and its impacts on service delivery in Busan Metropolitan City needs a multitude of steps at administrative and practical levels, and among others are as follows:

- Maintain and improve transportation services.

- Offer a smartcard: having a permanent ticket which you can top up and use without feeding through a gate or reader makes travel more efficient and provides better usage data as well, meaning we can develop services based on how people actually use them (Forgách, 2014).

- While solutions are often context-specific and every city will need to find ways to improve public transport based on detailed local needs and conditions, there are broad similarities in the strategies that almost all cities will benefit from the following. The following "threeintegrations" summarize the key focus areas and challenges facing Chinese cities, as they work to develop public transport systems that would support a low-carbon economy (The World Bank Group, 2012):

1) developing customer-oriented services: modern customer-oriented public transport enterprises can attract users of choice. This will require greater attention to the details of bus and rail transfer facilities, as well as the creation of premium services and a customeroriented mentality;

2) integrating schedules and fares across modes and services: although the use of multi-modal smartcards is common, bus interchange facilities that help passengers to change modes or services are systematically underused. In addition, fare policies are rarely designed to facilitate intermodal fare transfers. Integrated bus and rail services, schedules, and fares will contribute greatly to improved services for passengers;

3) integrating land use with transport planning: is increasingly evident that even the most effective systems of public transport cannot be competitive if they are not carefully integrated with land use planning and design.
- Land use patterns: The pattern of urban development has a major impact on the type of transit services that can be cost effectively provided. High population and employment densities allow for greater transit service potential. Generally, densities in the range of 4,500 people/workers per square mile increase the likelihood of success for traditional types of transit service. One of the ways of providing for these densities is through land use/growth management planning (Litman, 2005).

- Complementary policies: most evidence suggests that it is not sufficient simply to provide new transit services and it is expected that there will be a large rider response. Effective, transit-oriented transportation strategies must consider complementary policies that can make transit work. Of primary importance in this regard is managing the availability and cost of parking. When parking is perceived as being convenient and free, many commuters are going to continue to use their automobiles. Similarly, the price of gasoline is another factor that influences travel decisions. Transit improvements cannot be considered in isolation from other policies that probably have a more important impact on travel behavior than the transit improvement itself. The implementation of such complementary policies will most likely require a strong coalition of the governmental and business leaders in a region. Educating the public about the true costs of driving is a crucial step in gaining public support for transit (Litman, 2008).

- Stable funding: the most important factor in service expansion, and in maintaining existing levels of transit services, is the availability of a stable funding source. Litman (2008) believes that obtaining such a funding source is a difficult and time-consuming activity, given that it often requires voter approval (if taxes are involved) and/or permission from the state legislature. Transit general managers spend a great amount of time dealing with operations and capital budgeting, trying to develop innovative ways of obtaining the necessary level of funds to support transit services. Such efforts are important in that they relate directly to the fares that are charged for the services offered.

Conclusion. In the final conclusion and analysis of this study, the overall result shows that service quality attributes influences overall customer satisfaction in using public transportation system (PTS) (Nathanail, 2008). According to Anderson et al. (2013), high quality public bus transport not only keeps customer to continue using public bus transport to fulfill their travel demand, but also attracts potential customer. The examination of the literature provides some interesting results: behavior of personnel and, specifically, behavior 
of bus drivers, frequency of services, reliability of services, as well as time and particularly waiting time seemed to be the most crucial factors affecting customer satisfaction within other (Eboli and Mazzulla, 2011). These lead to the conclusion that Busan Transportation Corporation, to continue its satisfactory public transportation system service delivery for greater productivity and improved performance, must give due significance to these factors.

\section{Acknowledgement}

This study became more effective, because one of the authors (Kassian, T.T., Amesho) was based in South Korea in the Busan City, in particular, during the study in question, but he moved to Taiwan few months ago this year. So, he is presently based in Taiwan and is a DTech Candidate under the supervision of Emmanuel Innocents Edoun.

\section{References}

1. Alshalalfah, B. and Shalaby, A. (2005). Relationship between walk access distance to transit and socioeconomic, demographic and transit service characteristics, presented at the 84th Annual Meeting of Transportation Research Record. American Public Transportation Association (APTA) (2005) [Online]. Available at: http://www.apta.com/research/stats/fundcap/capfund.cfm. Accessed on $29^{\text {th }}$ March 2016.

2. Ancarani, A. and Capaldo, G. (2001). Management of standardised public services: a comprehensive approach to quality assessment, Managing Service Quality, 1(5), pp. 331-341.

3. Anderson, R., Condry, B., Findlay, N., Brage-ardao, R. and Li, H. (2013). Measuring and Valuing Convenience: A Review of Global Practices and Challenges from the Public Transport Sector [Online]. Imperial College London, United Kingdom. Available at: http://www.internationaltransportforum.org/jtrc/DiscussionPapers/DP201316.pdf. Accessed on $30^{\text {th }}$ March 2016.

4. Andreassen, T.W. (1995). (Dis) satisfaction with public services: The case of public transportation, Journal on Services Market, 9, pp. 30-41. DOI: 10.1108/08876049510100290.

5. Babbie, E.R. (2010). The Practice of Social Research. 12th ed. Belmont, CA: Wadsworth Cengage.

6. Busan Transportation Corporation. (2016). First-rate Public Utility for Citizens (Booklet). Busanjin-gu, Busan, Korea.

7. Cirillo, C., Eboli, L. and Mazzulla, G. (2011). On the asymmetric user perception of transit service quality, International Journal of Sustainable Transportation, 5, pp. 216-232.

8. Eboli, L. and Mazzulla, G. (2011). A methodology for evaluating transit service quality based on subjective and objective measures from the passengers point of view, Transport Policy, 18, pp. 172-181.

9. Eboli, L., and Mazzulla, G. (2007). Service quality attributes affecting customer satisfaction for bus transit, Journal of Public Transportation, 10(3), pp. 21-34.

10. Forgách, V. (2014). How to improve effectively the use of public transportation [online]. Available at: http://www.ectri.org/YRS07/Papiers/Session-10/Forgach.pdf. Accessed on 21 $1^{\text {st }}$ June 2016.

11. Gilbert, G. and Forester, J. (1977). The importance of attitudes in the decision to use mass transi, Transportation, 6(1977), pp. 321-332.

12. Lai, W-T. and Chen, F. (2011). Behavioral intentions of public transit passengers - The roles of service quality, perceived value, satisfaction and involvement, Transport Policy, 18, pp. 18-325.

13. Litman, T. (2008). Valuing transit service quality improvements, Journal of Public Transportation, 11, pp. 43-63.

14. Litman, T. (2005). Improved Public Transit [online]. Available at: https://www3.epa.gov/ otaq/stateresources/ policy/ transp/ tcms/ improved_transit.pdf. Accessed on $19^{\text {th }}$ June 2016.

15. Lu, C., Wei, G. and Wang, I. (2015). The Role of Self-Service Mobile Technologies in the Creation of Customer Travel Experiences, Technology Innovation Management Review.

16. Michel, Q. (2011). Globalisation and impact on public transport sector. University College of London [online]. Available at: http://www.ucl.ac.uk/qaser/events/pdf/presentations/quidort_seminar. Accessed on $07^{\text {th }}$ June 2016.

17. Miller, V. (2013). The leading force in advancing public transportation. Public Transportation is Leading the Way in Green Vehicles. Press Release [online]. Available at: http://www.apta.com/mediacenter/pressreleases/2013/Pages/130422_EarthDay.aspx. Accessed on $27^{\text {th }}$ May 2016.

18. Nash, A. (2006). Complimentary Measures to Support Public Transport [online]. Available at: https://improvepublic-transport.wikispaces.com/x8.\%20References. Accessed on $15^{\text {th }}$ June 2016.

19. Nathanail, E. (2008). Measuring the quality of service for passengers on the Hellenic Railways, Transportation Research Part A: Policy and Practice, 42(1), pp. 48-66.

20. Page-Bucci, H. (2007).The Value of Likert Scales in Measuring Attitudes of Online Learners. HKA Designs [online]. Available at: http://www.hkadesigns.co.uk/websites/msc/reme/likert.htm. Accessed on 20th April 2016.

21. Parasuraman, A., Zeithaml, V. and Malhotra, A. (2005). E-S-QUAL: a multiple-item scale for assessing electronic service quality, Journal of Service Research, 7 (3), pp. 213-233.

22. Parasuraman, A., Zeithaml, V.A. and Berry, L.L. (1988). SERVQUAL: A multiple-item scale for measuring consumer perceptions of service quality, Journal of Retailing, 64, pp. 12-40.

23. Pasek, J. (2012). Writing the Empirical Social Science Research Paper: A Guide for the Perplexed [online]. Psychology Teacher Network. Available at: http://www.apa.org/education/undergrad/empiricalsocial-science.pdf 
24. Roberts, G. (2003). Qualitative research in psychology: Expanding perspectives in methodology and design. Washington, DC: American Psychological Association.

25. Sahu, K.A. (2006). Perceptions of Service Quality in an Academic Library: A Case Study, Journal of Services Research, 6 (1), pp. 187-204.

26. The World Bank Group. (2012). Improving Public Transport in Chinese Cities: Elements of an Action Plan [online]. Available at: http://www.worldbank.org/en/news/feature/2012/08/14/improving-public-transport-inchinese-cities. Accessed on $19^{\text {th }}$ June 2016.

27. Vanniarajan, T. and Stephen, A. (2008). Railqual and passenger satisfaction: an empirical study in southern railways, Asia Pacific Business Review, IV (1), January-March, pp. 64-75.

28. Vijay, P.J. (2013). Measuring Commuters' Perception on Service Quality Using SERVQUAL in Public Transportation, International Journal of Marketing Studies, 3(1), pp. 1-14. Journal paper [online]. Available at: www.ccsenet.org/ijms. Accessed on 25th March 2016.

29. Zheng, L. and W, Jiaqing. (2007). Summary of the application effect of bus rapid transit at Beijing South-Centre corridor of China, Journal of Transportation System Engineering and Information Technology, 7, pp. $137-142$. DOI: $10.1016 / \mathrm{S} 1570-6672(07) 60034-8$. 